\title{
Division of Labour and Self-Reported Mental Requirements in Human Services: Retail Sale Jobs*
}

\author{
Ulrike Pietrzyk ${ }^{1}$, Sarah Rodehacke ${ }^{2,3}$, Winfried Hacker ${ }^{1}$ \\ ${ }^{1}$ Department of Psychology, Working Group "Thinking-Knowing-Acting”, Technische Universität Dresden, \\ Dresden, Germany \\ ${ }^{2}$ Department of Psychiatry and Psychotherapy, Technische Universität Dresden, Dresden, Germany \\ ${ }^{3}$ Neuroimaging Center, Technische Universität Dresden, Dresden, Germany \\ Email: ulrike.pietrzyk@tu-dresden.de
}

Received 27 May 2014; revised 23 June 2014; accepted 14 July 2014

Copyright (C) 2014 by authors and Scientific Research Publishing Inc.

This work is licensed under the Creative Commons Attribution International License (CC BY).

http://creativecommons.org/licenses/by/4.0/

c) (i) Open Access

\begin{abstract}
Significant associations between self-reported "whole units" of work and self-reported mental task requirements as well as personal outcomes are well known. Also of interest is, however, whether a significant association also exists between the underlying objective assignment of tasks, i.e. the division of labour, and self-reported mental requirements. Such an association would represent a concrete starting point for job design or redesign. We analyzed this question for retail sale jobs as an example of the numerous human service jobs, which usually consist of customerand object-centred tasks. The study ( $\mathrm{N}=558$ employees) evaluated the potential association between documented assignments of customer-centred and goods-centred activities and employees' perceived mental requirements, skill utilisation, and learning on the job, as well as mental difficulties. A significant association of moderate effect size between the objective division of labour and self-reported mental job requirements was shown. Theoretical and practical consequences of this association are also discussed.
\end{abstract}

\section{Keywords}

Division of Labour, Task Identity, Retail Sale Tasks, Task Analysis

\section{Introduction}

Revising the Job Characteristics Theory, Hackman and Oldham stressed that "one principle stands out as the

"In honour of the 85th birthday of Eberhard Ulich (Zurich, Switzerland)—senior of the German speaking psychology. 
fundamental pillar of the classic approach—and as the one that has the greatest implication for how work is designed in organisations. This, of course, is the principle of division of labour” (Hackman \& Oldham, 1980: p. 47).

\subsection{Division of Labour in Ergonomic Standards and Theoretical Background}

Recent international standards on ergonomic principles in the design of work systems (EN ISO 6385, 2004; DIN EN 614-2, 2002) call for jobs with whole units of work rather than fragments. Specifically, the standard DIN EN 614-2 (2002) demands that tasks should be entire and meaningful units of work with a clearly identifiable beginning and end. For this purpose jobs should not only include implementation, but also preparation (e.g. planning) and inspection of results (e.g. testing). Thus, work should allow for the utilization of an appropriate combination of the levels of mental control, i.e. of skill-based procedures, rule-based procedures, as well as knowledge-based development of new solutions. These recommendations should be implemented in work design by the assignment of different operations to individuals or in work redesign by job rotation, job enlargement, or job enrichment (DIN EN 614-2, 2002: Appendix A, Sections 2.2, 3.2, 3.6.3).

The recommendations of these standards correspond with former suggestions of Action Regulation Theory (ART) (Frese \& Sabini, 1985; Ginsburg et al., 1985; Hacker, 2003) based on research of Lewin and his coworkers (Lewin, 1926; Lewin \& Rupp, 1928) and neuropsychological contributions of Luria (1973). ART describes the components (mental processes and representations), steps (goal setting, planning and decision making (control), implementation, checking of results and levels (deliberate, intuitive, and automated) of mental action regulation. A key concept is the "entire task" or "task identity". The impact of individual components of tasks (especially demands vs. control) on task outcome and well-being is specified in the Job Demand-Control (JDC) and in the enlarged Job Demand-Control Support (JDCS) model (Karasek \& Theorell, 1990). An extension of these models is the Job Demands-Resources (JD-R) model (Bakker \& Demerouti, 2007; Bakker et al., 2010) which allows considering job-specific configurations of demands and resources.

\subsection{Self-Reported Task Identity}

More recent studies analyzed the relationship between employees' self-reports on whole units or pieces of work or on self-reported task identity and other self-reported job characteristics and job outcomes (e.g. Hackman \& Oldham, 1980; Sims et al., 1976). Self-reported task identity reflects the degree to which a job involves a whole piece of work. The Work Design Questionnaire (Morgeson \& Humphrey, 2006), as well as its German equivalent (Stegmann et al., 2010), offer several items paraphrasing this concept ("to do an entire piece of work"; "to completely finish pieces of work" with "an obvious beginning and end" and "to complete work I start"; Morgeson \& Humphrey, 2006: p. 1337). Meta-analyses report significant relationships between self-reported whole pieces of work and other self-reported job characteristics and work outcomes (Bakker et al., 2010; Cordery \& Parker, 2012; Humphrey et al., 2007; Morgeson \& Humphrey, 2006). These other self-reported job characteristics include skill and task variety, feedback of results, significance of tasks, and autonomy. They are mentioned in the cited standards, too.

However, there are theoretical problems with the evidence showing relationships between self-reported task identity and further self-reported job characteristics. These relationships could be biased by common method bias (Podsakoff et al., 2003): Self-reports on task identity and, for example, task variety or significance may interact. Moreover, from a practical point of view, in job design or redesign the objective assignment of tasks to individuals is designed, but not self-reported task identity (Schuller et al., 2012). Therefore, in contrast, in this study we examined the association between the more objective division of labour, i.e. the assignment of tasks to individuals in job design, and self-reported mental task requirements.

\subsection{Existing Research on Division of Labour}

There have been few empirical studies on division of labour since 2000, and most of these considered division of labour in order to characterize the consequences of organisational design. For example, a longitudinal study in the healthcare system (Bolton, 2004) analyzed nurses' responses to changes in nursing labour through the use of Tayloristic techniques of division of labour. Another study in the healthcare system (Berkhout et al., 2003) reported a partly task-oriented division of labour in psychogeriatric wards through the implementation of residentoriented care. A longitudinal study by Carter \& Stevenson (2012) examined restructuring of teachers' work to 
reduce work load pressures. Rather than this outcome, the result was the further division of labour with increasing intensity and control of teachers' work. A study by Cacciatori et al. (2012) showed that strong industry norms governing division of labour discourages knowledge transfer.

A smaller second group of studies experimentally examined the division of labour between psychophysical systems controlling action (Goodale \& Westwood, 2004; Brusoni, 2005).

A few studies investigated division of labour between the divisions of firms (Grimaldi \& Torrisi, 2001), the inter- and intra-professional division of labour especially considering professional autonomy of nurses in the health service (Martin et al., 2009; Salhani \& Coulter, 2009), and gender differences in division of labour in the household (Grönlund, 2012).

However, no contributions explicitly investigated relationships between division of labour in terms of task assignment to individuals and employees' self-reported mental job characteristics in terms of skill or task variety, autonomy or use of skills. Moreover, the utilisation of existing organisational documents regarding assignment of tasks to employees, for example job descriptions, employment contracts or salary reports, is not reported.

\subsection{Objectives of the Study and Hypotheses}

The main goal of this study is to test whether the reasonably objective division of labour, i.e. the assignments of tasks to employees, determine employee self-reported mental task requirements. We expect that employee selfreports on possibilities of mental task regulation, skill utilisation and learning, and difficulties in mental regulation (short mental requirements) significantly correspond with the configurations of tasks assigned to them, which may be identified in documented job descriptions.

Specifically, the mental requirements we are interested in are scales of the FEMIA questionnaire (Pietrzyk et al., 2012). The scales of this questionnaire are theoretically based on the Job Demand-Control approach and its generalisation, the JDR approach (Demerouti et al., 2001) and on ART (Frese \& Sabini, 1985, Ginsburg et al., 1985; Hacker, 2003), as well as on research in emotion work (Gross, 1998a, 1998b; Zapf et al., 2000). The scales are related to perceived mental job requirements, skill utilisation and learning on the job, and difficulties in mental task regulation.

In order to relate division of labour to the mental task requirements, we operationalized and graded the concept of "whole units of work" as follows:

- whole unit of work (complete activity): preparation (P) + implementation (I) + checking (C) of a task and the results;

- incomplete activity: P + I or I + C;

- fragment of a whole unit of work: one individual component only (mainly I).

This scale is part of a family of instruments for work analysis (Task Assessment System; Hacker et al., 1995; Richter \& Hacker, 2003; Debitz et al., 2001).

Since around three-fourths of employees in Germany are working in the human services sector, the first goal of our study is to investigate division of labour in this area. We use the example of retail sale with more than 3,000,000 employees in Germany (IHK Chemnitz, 2014). Here, employees carry out interactive tasks with customers as well as tasks with goods. Thus, an operationalization of division of labour considering both objects of labour is required. Examples of tasks with customers in retail sale jobs are serving or taking payment at the cash desk. Examples of non-customer related tasks are stocking shelves or ordering goods. The assignment of tasks with and/or without customers to employees may influence not only perceived task identity, but also perceived variety of mental requirements, and perceived mental difficulties. Emotional dissonance, for example, may become a difficulty in the interactive components of a job only. Thus, in the human services sector two aspects of division of labour are combined: The general aspect of allocation of different tasks to individuals, and the specific aspect that these tasks may concern different objects of labour, customers or goods.

Regarding interactive tasks with customers, we assume a whole unit of work in retail sale jobs means the entire selling process, including serving and advising customers concerning characteristics of goods, as well as taking payment. A fragment of the whole selling job may be taking payment without serving or advising. This distinction describes two levels of entirety of retail sale jobs. Regarding goods-centred tasks we assume a whole unit of work means watching stocks, ordering goods, checking quality, and restocking: A fragment may be restocking only.

Extending the conception of Hackman and Oldham (1980) and the cited standards we expect that the less 
fragmentary the tasks assigned to employees are, the more strongly they should report task requirements regarding mental task regulation, skill utilisation and learning, and regulation difficulties.

Specifically, we predict for retail sale jobs:

H. 1.1: Less fragmentary goods-centred task configurations correspond with significantly more explicitly self-reported requirements on mental regulation, skill utilisation and learning, and regulation difficulties.

H. 1.2: Less fragmentary interactive customer-centred task configurations correspond with significantly more explicitly self-reported mental requirements.

Given the two objects of labour, goods and customers, sales persons' division of labour should be operationalized with a combination of the mentioned two scales of whole units of work versus fragments (see in Table 2 head column and left row). The combination of customer-centred fragments with goods-centred fragments of entire jobs in supermarkets may enlarge sales persons' task variety (Zaniboni et al., 2013) and, thus, increase self-reported mental requirements.

Beyond enlarged task variety, integrating interactive and goods-centred tasks may result in a whole unit of work. For example: In supermarkets with self-service the combination of taking payment (customer-centred) with restocking (goods-centred)—fragments of goods- and customer-centred work respectively—will result in an entire piece of work. We predict:

H. 1.3: The combination of fragments of entire customer-centred work with fragments of entire goods-centred work increases employees' self-reported mental job requirements.

In organisations several descriptions of the assignment of tasks to employees exist, mainly in the form of employment contracts, payment documents, or job descriptions for further training. In most cases this data are updated over time, since it is necessary for various management activities, for example in decisions regarding substitution, vacancies or on further training. Such documentations allow for the objective operationalization of division of labour. We assigned employees' task configurations to the scales of goods-centred and customer-centred tasks, mentioned above and in Table 2 (left column and first line). Moreover a comparison of several documentations on tasks assigned to individuals may allow for checking and correcting these categorisations of task assignment. Thus, we predict:

H. 2: Trained raters (organisational psychologists) assign retail sale jobs based on organisations' existing job descriptions to the categories of division of labour (see Table 2; defined by a combination of customercentred and goods-centred tasks) with at least substantial inter-rater reliability (kappa $\kappa=0.60-0.79$ ).

Regarding our first hypothesis, H. 1.1, a limitation should be considered. Positive self-reported effects of whole units of work and accordingly low division of labour concerning mental job requirements may be limited. We predict:

H. 3: Adding further tasks to task configurations which are already whole units of work will not result in a significant increase of self-reported skill utilisation and learning, mental regulation requirements, or regulation difficulties.

Finally, drawing on ART the relationship between whole units of work versus fragments and self-reported mental requirements will be valid for a variety of conditions, i.e. for different organisations with different conditions of work and work-relevant characteristics of employees. Therefore we predict:

H. 4: The relationship between objective task configurations and self-reported mental task requirements predicted in H. 1.1 - 1.3 and 3 will apply for food versus non-food retail sale enterprises, with employees differing significantly in age, tenure, training on retail sale jobs, and part-time employment.

\section{Methods}

\subsection{Sample}

We analyzed two retail sales enterprises. A sample of 433 employees of a German food retail enterprise with 33 branches volunteered for this study. The mean age of this sample was 37.5 years ( $\mathrm{SD}=12.9$, range 18 - 65). The participants' average job tenure was 17.9 years $(S D=11.9)$ and in their present enterprise 8.4 years $(\mathrm{SD}=7.1)$. 
84\% were female, $89 \%$ were trained in retail sales, and the minority of participants (36\%) worked on a full-time basis.

The second sample of 125 employees was employed in a non-food (chemists) retail enterprise with eight branches. The mean age of this sample was 28.1 years $(\mathrm{SD}=0.9$; range $17-60)$, the average job tenure was 7.9 years $(S D=0.7)$, and in their present enterprise 4.4 years $(S D=0.4)$. Here $90 \%$ were female, $70 \%$ were trained in retail sales, and the majority (59\%) worked on a full-time basis.

The two samples differ significantly $(p<0.01)$ in employees' age, tenure, training in retail sales, and part-time employment, but not in gender (see Table 1). Therefore, in a first step the results will be described separately for both samples. Thus, it becomes evident whether the relations between division of labour and self-reported mental task requirements are consistent in spite of differences in employees' age, tenure, training, and part-time employment as well as enterprise.

The participants were recruited via announcements at staff meetings, and participation was voluntary. The goods sold in both enterprises did not need extensive advice or instruction of customers, though occasional advising here is a component of serving.

\subsection{Study Design and Variables}

We applied a cross-sectional multi-method design. Data were collected between 2009 and 2010.

The independent variable was the firms' assignments of tasks to employees, documented in job descriptions of employment contracts and salary brackets. The categorisation of employees' task configurations concerning division of labour, i.e. fragmentation vs. entirety of work, was made independently by two trained organisational psychologists and inter-rater reliability was tested.

The dependent variables were employee self-reported mental task requirements. These requirements are determined by questionnaire, which was administered individually during normal working hours. Employees agreed to participate; the employee representations permitted the study.

All participants were assured that their responses would remain confidential.

\subsection{Instruments}

The perceived task requirements were assessed using the theoretically based Retail Sale Questionnaire "FEMIA" (Pietrzyk et al., 2012). The questionnaire consists of 25 items organized into three scales: "skill utilisation and learning possibilities", "requirements on mental regulation", and "difficulties in mental regulation and emotional dissonance". Difficulties include conflicting requirements, requirements due to customer interruption of tasks, and time pressure. The items regarding emotional dissonance are a scale of the Frankfurt Emotional Work Scales (FEWS, Zapf et al., 2000) and are added with permission from the authors.

The items of the first two scales describe requirements of well-designed tasks following the standard EN ISO 6385 (2004). The third scale describes task requirements which should be reduced in order to avoid overload. An example of the first scale $(\alpha=0.88)$ is the item "My job provides the acquisition of new skills", an example of the second one $(\alpha=0.81)$ is the item "My job includes planning the tasks", and an item of the third scale $(\alpha=$ 0.67 ) is "In my job it is important to hide arising emotions from customers".

Table 1. Sociodemographic data of employees of the samples (sample 1: food retail enterprise; sample 2: chemists retail enterprise).

\begin{tabular}{|c|c|c|c|}
\hline & Sample 1 & Sample 2 & Statistical test \\
\hline Gender (female \%) & 84 & 90 & $\chi^{2}=2.56$ \\
\hline Age (mean (M), standard error (SE)) & $37(13)$ & $28(11)$ & $\mathrm{t}=8.26^{* * *}$ \\
\hline Tenure job (M) & 18 & 7 & $\mathrm{t}=12.12^{* * *}$ \\
\hline Tenure enterprise (M) & 8 & 4 & $\mathrm{t}=5.08^{* * *}$ \\
\hline Employment (\%) (full time/part time/marginally) & $30 / 64 / 6$ & $27 / 40 / 33$ & $\chi^{2}=73.21^{* * *}$ \\
\hline Vocational training in retail sales (\%) & 89 & 70 & $\chi^{2}=5.62^{* * *}$ \\
\hline
\end{tabular}

Note: ${ }^{*} p<0.05,{ }^{* *} p<0.01,{ }^{* * *} p<0.001$. 
The employees assessed their jobs through items of the questionnaire on a rating scale with five categories varying between "completely disagree” and "completely agree”. In order to compute means, we assigned a numeric value of 1 to 5 to the answers, with 1 representing “completely disagree” and 5 representing "completely agree”.

\subsection{Statistical Analyses}

In a first step we determined for both samples the percentages of employees carrying out jobs with different configurations of tasks as to their objects of labour and their entirety vs. fragmentation (cf. Table 2). Then, for each group of employees (each cell of Table 2) means and standard deviations were computed. Next, normal distribution is tested (Kolmogorov-Smirnov-Test; if necessary Lilliefors correction). The significance of differences between the means of two groups is assessed by Mann-Whitney-U-Tests. Following Diehl and Arbinger (2001) for the comparison of three groups we applied ANOVAs with the Brown-Forsythe-Test. Depending on homogeneity of variances the post-hoc tests follow Tukey or Tamhane (Diehl \& Arbinger, 2001). The level of significance is adapted by the Bonferroni correction. Rank order correlations apply the Spearman rho-coefficient.

\section{Results}

\subsection{Identification of Division of Labour Based on Documentary Data}

The levels of division of labour were identified by two organisational psychologists based on organisations' documentary data with good inter-rater reliability $(\kappa=0.79)$, therefore verifying hypothesis 2 .

\subsection{Distribution of Employees Carrying out Jobs Differing in Fragmentation vs. Entirety}

Table 2 shows the distribution of the employees in the food retail sale enterprise and the non-food enterprise on jobs with differing objects of labour and fragmentation vs. entirety.

Most jobs (93\%) combine interaction-centred and goods-centred tasks. However, most jobs are fragments of the entire selling process due to the self-serving principle: $72 \%$ of the jobs with interaction-centred tasks require only taking payment. Similarly, all jobs with goods-centred tasks only are only fragments of entire tasks, being restricted to implementation without preparation, organisation, and checking.

\subsection{Task Configurations of Different Fragmentation vs. Entirety and Self-Reported Mental Requirements}

To investigate the relationship between division of labour and self-reported mental requirements, we compare the objective task configurations as to employees' self-reported requirements. These comparisons are made separately for the two samples. Table 3 gives an overview of means (M) and standard errors (SE) within the different configurations of tasks for both samples.

First, configurations with identical interaction-centred, but differing goods-centred entirety are compared:

\subsubsection{Differing Goods-Centred But Identical Interaction-Centred Entirety}

With higher goods-centred entirety of the sales jobs, the employees' assessments of "skill utilisation” (scale 1) and of "requirements made on mental regulation" (scale 2) were higher. Moreover, employees with higher goods-centred entirety of their jobs reported more explicitly “mental difficulties” (scale 3), especially regarding interruptions and contradictory requirements. This is shown in Figure 1 for the food sample.

The differences in the food sample were significant for all scales (scale 1: $\mathrm{F}(1,431)=96.5, p<0.01, \eta_{p}^{2}=$ 0.40 ; scale 2: $\mathrm{F}(1,431)=10.0, p<0.01, \eta_{p}^{2}=0.39$; scale $\left.3: \mathrm{F}(1,431)=10.95, p<0.01, \quad \eta_{p}^{2}=0.07\right)$. Strong effect sizes (partial eta-squares) exist for scales 1 and 2 only.

The non-food sample showed similar results. Figure 2 compares the mean assessments of sales people who are taking payment in combination with various executing activities with the assessments of employees carrying out payment taking combined with executing activities, planning activities, and activities organising cooperation. Again, the mental job requirements of the less fragmentary configuration were higher than those of the more fragmentary one. Concerning scale 1 (application of qualification/learning possibility on the job/feedback), a 
Table 2. Number of employees carrying out retail sale jobs with different configurations of tasks (sample 1: food retail enterprise; sample 2: chemists retail enterprise).

\begin{tabular}{|c|c|c|c|c|c|c|c|c|c|}
\hline \multirow{2}{*}{\multicolumn{2}{|c|}{$\begin{array}{c}\text { Tasks without } \\
\text { customers } \\
\text { (goods-centred tasks) }\end{array}$}} & \multicolumn{6}{|c|}{ Tasks with customers (interaction-centred tasks) } & \multirow{2}{*}{\multicolumn{2}{|c|}{ Sum }} \\
\hline & & \multicolumn{2}{|r|}{ None } & \multicolumn{2}{|c|}{ Taking payment } & \multicolumn{2}{|c|}{$\begin{array}{l}\text { Serving with advice } \\
\text { and taking payment }\end{array}$} & & \\
\hline None & $\begin{array}{l}\text { Sample } 1 \\
\text { Sample } 2\end{array}$ & & & $\begin{array}{l}0 \\
0\end{array}$ & \} 0 & $\begin{array}{l}0 \\
0\end{array}$ & \} 0 & $\begin{array}{l}0 \\
0\end{array}$ & \} $0(0 \%)$ \\
\hline IO & $\begin{array}{l}\text { Sample } 1 \\
\text { Sample } 2\end{array}$ & $\begin{array}{l}0 \\
0\end{array}$ & \} 0 & $\begin{array}{c}47 \\
1\end{array}$ & 48 & $\begin{array}{l}0 \\
0\end{array}$ & \} 0 & $\begin{array}{c}47 \\
1\end{array}$ & \} $48(9 \%)$ \\
\hline IS & $\begin{array}{l}\text { Sample } 1 \\
\text { Sample } 2\end{array}$ & $\begin{array}{c}0 \\
40\end{array}$ & \} 40 & $\begin{array}{c}193 \\
69\end{array}$ & 3262 & $\begin{array}{c}90 \\
0\end{array}$ & \} 90 & $\begin{array}{l}283 \\
109\end{array}$ & \} $392(70 \%)$ \\
\hline $\mathrm{IS}+\mathrm{P}+\mathrm{C}$ & $\begin{array}{l}\text { Sample } 1 \\
\text { Sample } 2\end{array}$ & $\begin{array}{l}0 \\
0\end{array}$ & \} 0 & $\begin{array}{l}76 \\
15\end{array}$ & \} 91 & $\begin{array}{c}27 \\
0\end{array}$ & \} 27 & $\begin{array}{c}103 \\
15\end{array}$ & \} 118 (21\%) \\
\hline Sum & $\begin{array}{l}\text { Sample } 1 \\
\text { Sample } 2\end{array}$ & $\begin{array}{c}0 \\
40\end{array}$ & \} $40(7 \%)$ & $\begin{array}{c}316 \\
85\end{array}$ & \} $401(72 \%)$ & $\begin{array}{c}117 \\
0\end{array}$ & \} $117(21 \%)$ & $\begin{array}{l}433 \\
125\end{array}$ & \} $558(100 \%)$ \\
\hline
\end{tabular}

Note: IO: Implementation of only one task; IS: Implementation of various tasks; IS + P + C: Implementation, preparation + checking.

Table 3. Configurations of goods- and interaction-centred tasks of retail sale jobs and self-reported task requirements (M, $\mathrm{SE})$, sample 1: food retail enterprise; sample 2: chemists retail enterprise.

\begin{tabular}{|c|c|c|c|c|c|c|c|c|}
\hline & & \multicolumn{7}{|c|}{ Self-reported job requirements } \\
\hline & & \multirow[t]{2}{*}{$\begin{array}{l}\text { Number of } \\
\text { employees }\end{array}$} & \multicolumn{2}{|c|}{$\begin{array}{l}\text { Skill utilisation and } \\
\text { learning possibilities }\end{array}$} & \multicolumn{2}{|c|}{$\begin{array}{l}\text { Requirements on } \\
\text { mental regulation }\end{array}$} & \multicolumn{2}{|c|}{$\begin{array}{c}\text { Difficulties in mental regulation, } \\
\text { emotional dissonance }\end{array}$} \\
\hline \multicolumn{2}{|l|}{ Configurations of tasks (cf. Table 2) } & & M & SE & M & SE & M & SE \\
\hline $\mathrm{IO}+$ taking payment & Sample 1 & 47 & 2.39 & 0.54 & 2.34 & 0.60 & 2.48 & 0.48 \\
\hline IS + no interaction-centred tasks & Sample 2 & 40 & 2.78 & 0.64 & 2.37 & 0.64 & 2.44 & 0.46 \\
\hline \multirow{2}{*}{ IS + taking payment } & Sample 1 & 193 & 3.41 & 0.40 & 2.91 & 0.74 & 2.70 & 0.56 \\
\hline & Sample 2 & 69 & 3.74 & 0.42 & 3.36 & 0.52 & 3.02 & 0.55 \\
\hline IS + serving/advice, payment & Sample 1 & 90 & 4.02 & 0.33 & 3.34 & 0.57 & 2.65 & 0.61 \\
\hline \multirow{2}{*}{ IS/P/C + taking payment } & Sample 1 & 76 & 3.99 & 0.44 & 4.17 & 0.74 & 3.00 & 0.55 \\
\hline & Sample 2 & 15 & 4.02 & 0.48 & 4.29 & 0.50 & 3.25 & 0.69 \\
\hline IS/P/C + serving/advice, payment & Sample 1 & 27 & 3.96 & 0.60 & 4.36 & 0.53 & 3.10 & 0.68 \\
\hline
\end{tabular}

Note: IO: Implementation of only one task; IS: Implementation of various tasks; IS + P + C: Implementation, preparation + checking.

marginal significant difference exists $(U=357.00, p=0.06)$. The differences concerning scale 2 (requirements on mental regulation) and scale 3 (mental difficulties) are significant $(\mathrm{U}=104.00, p<0.01$; $\mathrm{U}=343.00, p<$ $0.05)$.

In the next step we investigated the effects of differing customer-centred entirety, but identical goods-centred one:

\subsubsection{Identical Goods-Centred But Differing Customer-Centred Entirety}

In the food sample the employees assessed "application of qualification/learning on the job" (scale 1) and "required mental regulation" (scale 2) significantly higher for a configuration of tasks with higher customer-centred entirety than for the less customer-centred one (scale 1: $U=2975.00, p<0.01$; scale 2 : $U=6308.00, p<0.01$ ). No significant differences exist concerning "mental difficulties" (scale 3) $(\mathrm{U}=5983.50, p=0.092)$ between employees who were only taking payment and those who were additionally serving (see Figure 3). 
task configurations:

- taking payment + one executing task

$\square$ taking payment + various executing tasks

睡 taking payment + executing, preparing, organizing/inspection tasks

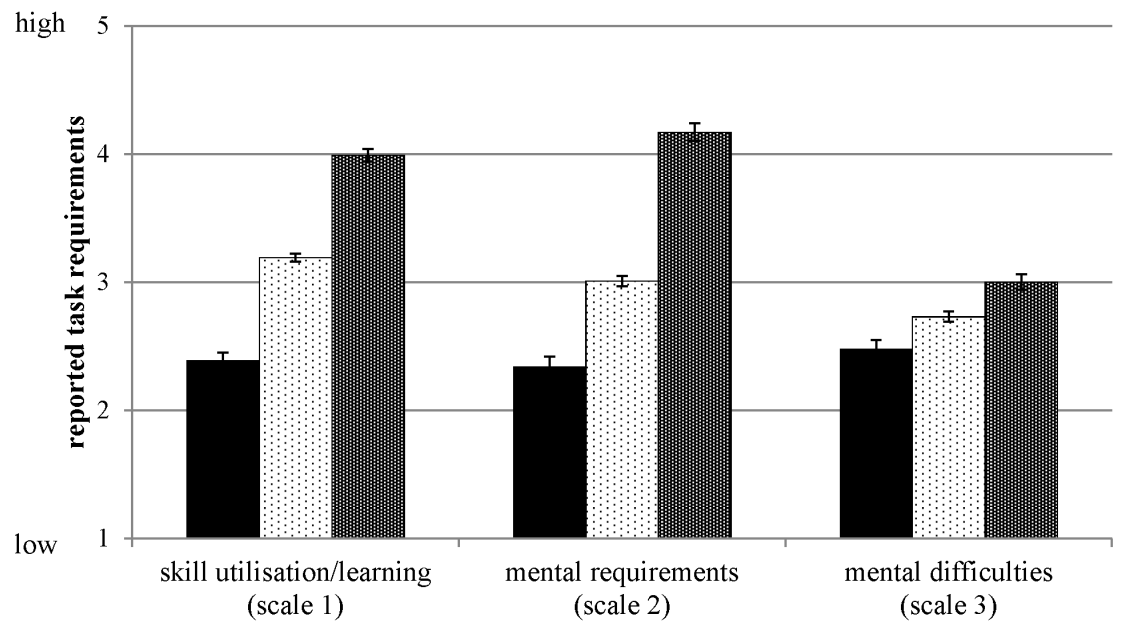

Figure 1. Reported task requirements (scales 1 - 3) of three task configurations with different goods-centred entirety and identical interaction-centred entirety (food sample, mean \pm standard error). For description of scales see Methods section, for numeric values Table 3.

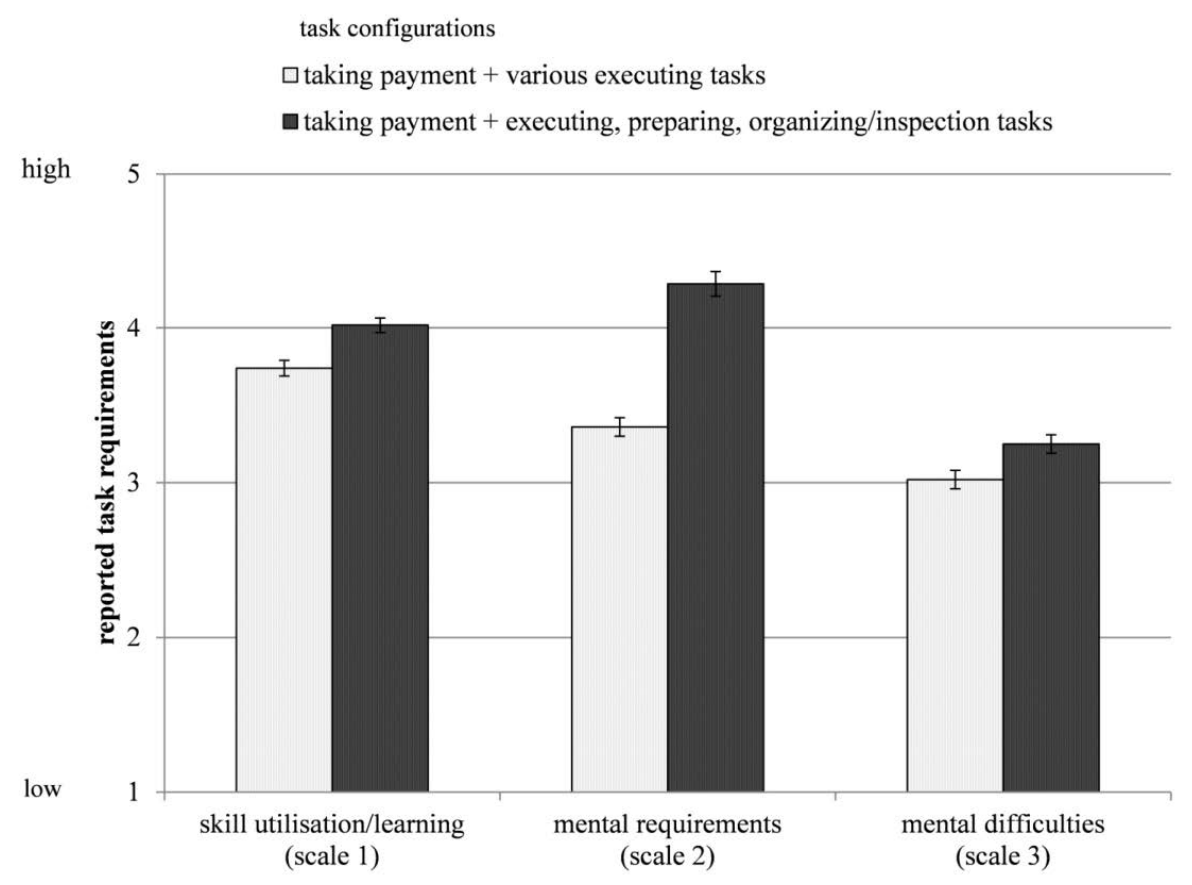

Figure 2. Reported task requirements (scales 1 - 3) of two task configurations with different goods-centred entirety and identical interaction-centred entirety (non-food sample, mean \pm standard error). For description of scales see Methods section, for numeric values Table 3.

In the non-food sample it is possible to compare tasks with identical goods-centred entirety (i.e. tasks with various executing activities), but existing vs. missing customer-centred tasks (taking payment vs. no interaction with customers at all (see Figure 4)). The differences are significant for the three scales (scale 1: application of qualification/learning possibilities/feedback: $\mathrm{U}=321.50, p<0.01$; scale 2 : requirements made on mental regulation: $\mathrm{U}=400.00, p<0.01$; scale 3: mental difficulties: $\mathrm{U}=586.50, p<0.05$ ). 


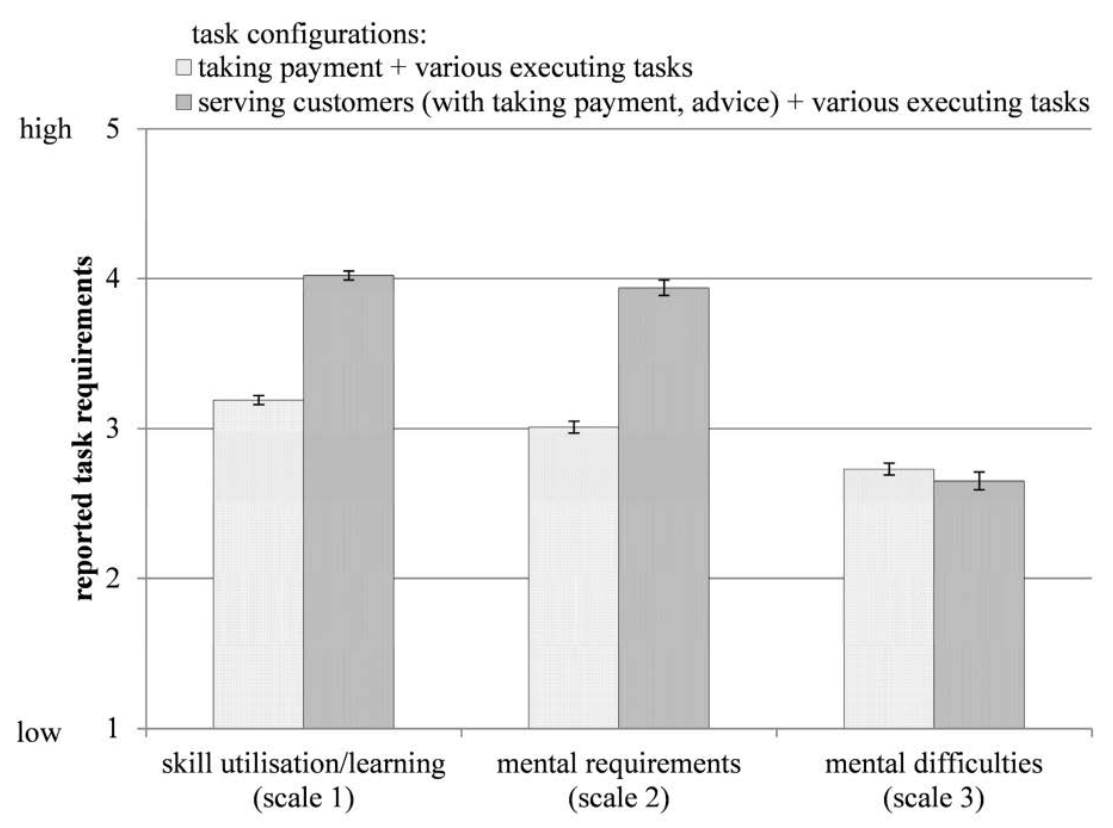

Figure 3. Reported task requirements (scales 1 - 3) of two task configurations with different interaction-centred entirety but identical goods-centred entirety (food sample, mean \pm standard error). For description of scales see Methods section, for numeric values Table 3.

task configurations:

$\square$ without customer interaction + various executing tasks

$\square$ taking payment + various executing tasks

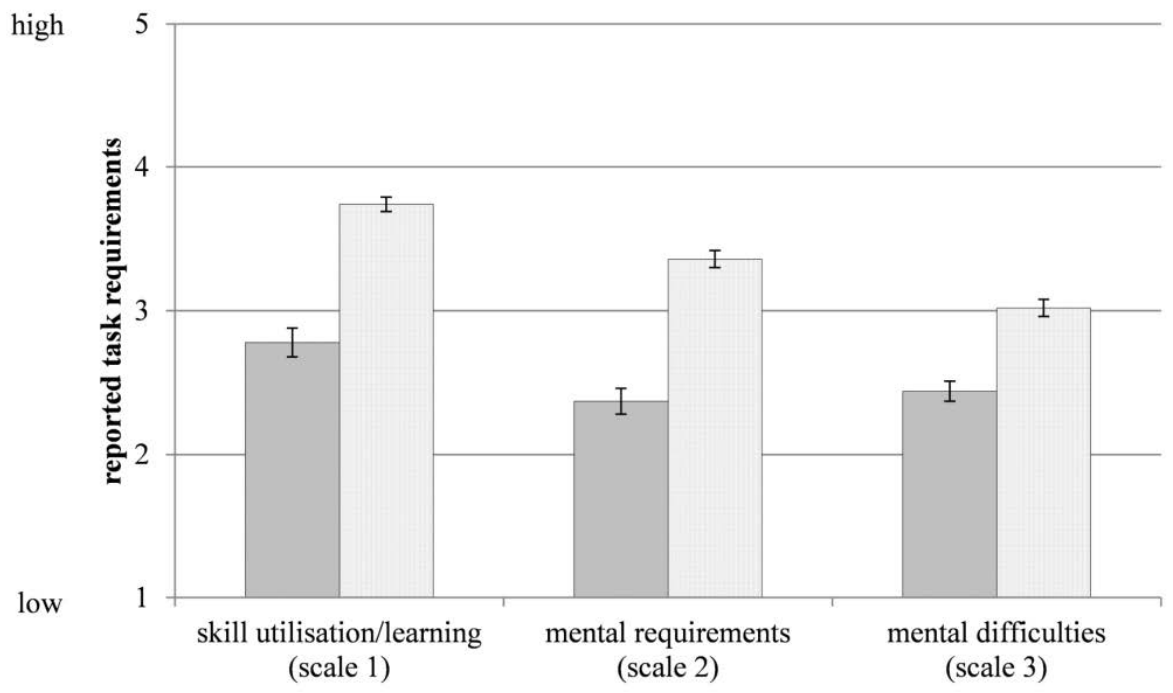

Figure 4. Reported task requirements (scales 1 - 3) of two task configurations with different interaction-centred entirety but identical goods-centred entirety (non-food sample, mean \pm standard error). For description of scales see Methods section, for numeric values Table 3.

The results presented so far are in favour of hypotheses 1.1 and 1.2: Less fragmentary goods-centred as well as customer-centred documented units of work correspond with significantly more pronounced self-reported mental job requirements, skill utilisation/learning and-with one exception-mental difficulties.

Moreover, the combination of fragments of goods-centred processes with fragments of customer-centred processes results in more pronounced self-reported mental job requirements (for example see Figure 4: various goods-centred operations only versus these operations + taking payment). This is in favour of hypothesis 1.3. 
In contrast, the combination of whole goods-centred task configurations with whole customer-centred ones does not result in a significant increase of self-reported mental job requirements, compared with the combination of a whole goods-centred task configuration with a customer-centred fragment (taking payment) only (scale 1: $\mathrm{U}$ $=789.00, p=0.98$; scale 2: $\mathrm{U}=911.00, p=0.38$; scale $3: \mathrm{U}=816.00, p=0.84$ ) (see Figure 5). This limitation of the further increase of self-reported job requirements is in favour of hypothesis 3 .

So far, we analyzed the associations between objective division of labour and self-reported task requirements separately for the two samples. In the next step all identified configurations of tasks of both samples are arranged based on their division of labour. Then rank order correlations between the ranks of the entirety of all identified task configurations and the ranks of the relevant self-reported mental task requirements are computed.

\subsubsection{Relations between Division of Labour and Self-Reported Mental Requirements for the Entire Sample}

Figure 6 summarizes the means of employee assessments of self-reported mental task requirements (scales 1 - 3) for all identified task configurations. For this summary, a rank order was assigned to the configurations: the more fragmentary the jobs, the lower their rank.

Significant associations were shown between increasing entirety of their jobs and employee reported skill utilisation and further learning on the job (scale 1), as well as requirements made on mental regulation (scale 2). However, there was no significant correlation between job entirety and mental difficulties (scale 3). Thus, considering the whole sample, the significant increase of mental difficulties with higher job entirety (lower division of labour) mentioned above (see Figure 1 and Figure 4) is not supported.

\subsection{Relations of Division of Labour to Self-Reported Task Requirements in Different Samples}

As was outlined in the Methods section, the two samples of this study differ in characteristics of the supermarkets (food versus chemist's retail sale; different size of enterprises) as well as employees' mean age, tenure, training, and part-time employment.

Due to these differences, the validity of obtained result should be tested with task configurations of the same kind in both samples. Only two uniform pairs of task configurations were identified in both samples. These are "taking payment + some goods-centred implementation tasks" versus "taking payment + some implementation tasks and preparing as well as checking tasks”.

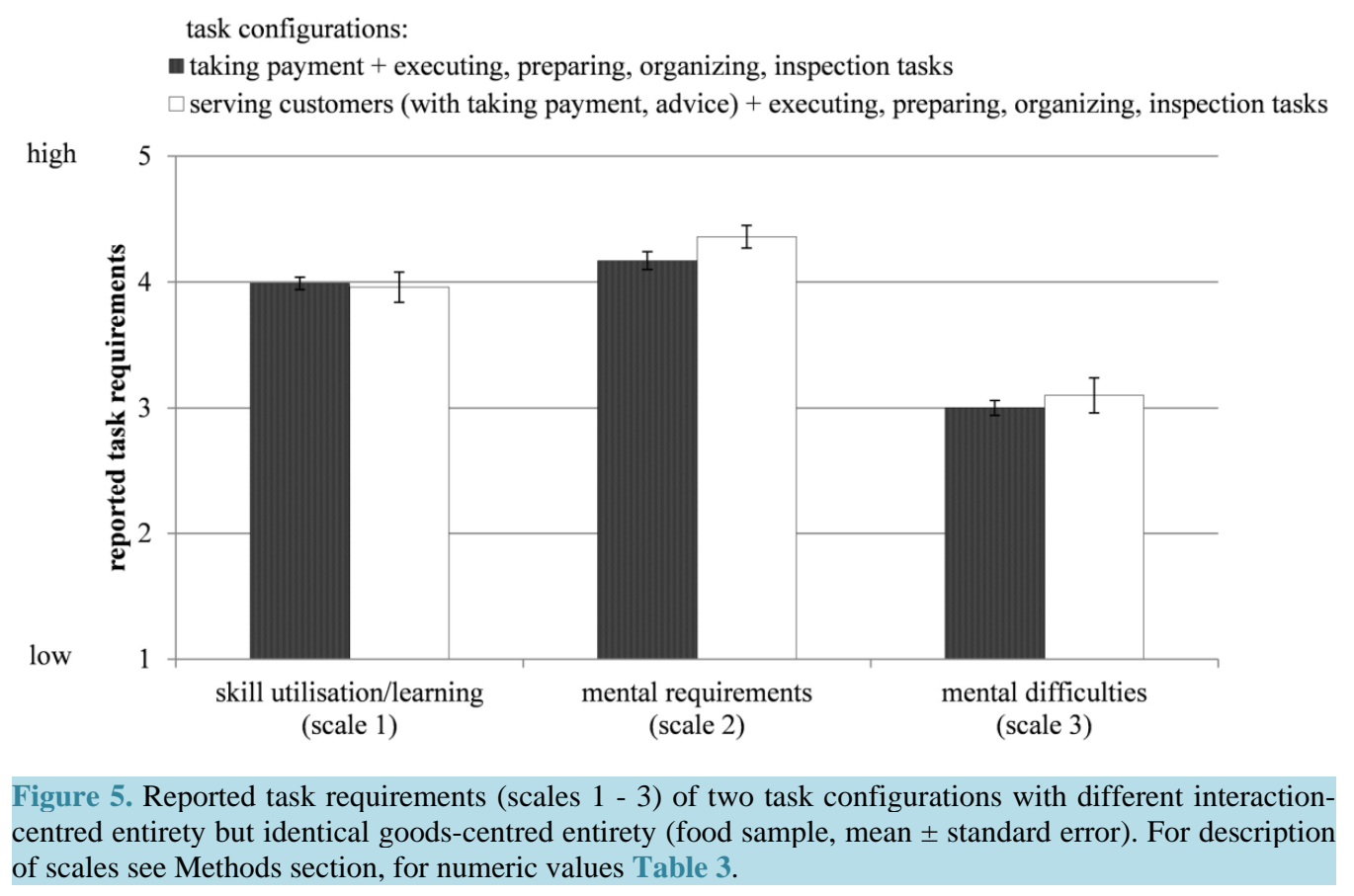




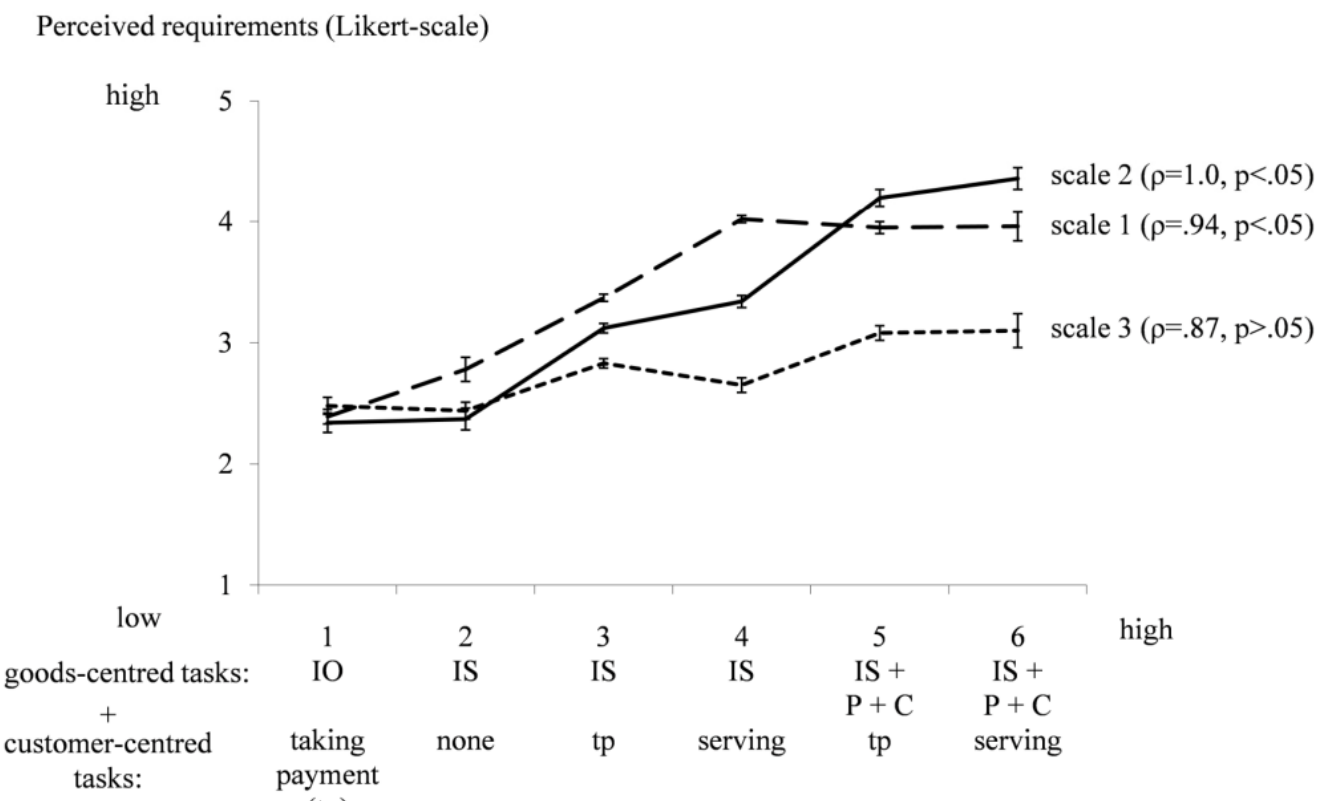

(tp) Job entirety (rank order)

Figure 6. Employee mean self-reported task requirements depending on a rank order of job entirety (whole sample). Scale 1: Skill utilisation/further learning on the job; scale 2: Mental requirements; scale 3: Difficulties in mental regulation. IO: Implementation, one activity; IS: Implementation, several activities; P: Preparing goods-centred activities; C: Checking goods-centred activities.

Figure 1 and Figure 2 show no differences in the nature of the relationship between division of labour and self-reported mental job requirements. In both samples the reported requirements are higher with less fragmentary task configurations in spite of the aforementioned organisational and individual differences of these samples. Thus, Hypothesis 4 is supported for these cases.

\section{Discussion}

Our study contributes to existing literature in at least four aspects with theoretical as well as practical meaning:

First, we introduce a more objective measure of division of labour. Division of labour, i.e. the assignment of tasks to individuals, is the central decision in job design or redesign.

Most contributions so far relate self-reports on whole units or entire pieces of work, i.e. task identity, to other self-reported job characteristics or job outcomes (e.g. Humphrey et al., 2007; Morgeson \& Humphrey, 2006). Morgeson \& Humphrey (2006) presented a summary on relations of self-reported task identity, further self-reported task characteristics, work outcomes and correlates developing and validating their Work Design Questionnaire.

A more objective measure of task assignment to individuals may avoid common method bias in job design research (Podsakoff et al., 2003).

Second, for reasons of job design it is inevitable to know what an entire piece or whole unit of work actually comprises, and a scale with levels of job entireness may be useful. We proposed a more objective and concrete operationalization of division of labour following ART (Frese \& Sabini, 1985; Lewin, 1926; Hacker, 2003). Following this approach an entire job comprises not only implementation of assigned tasks, but also their preparation (goal setting, planning, decision making), organisation of cooperation, and checking of results. The lowest level of job entireness, thus, is pure implementation. This measure stands the test with industrial and administrative tasks without customers (Debitz et al., 2001; Richter \& Hacker, 2003; Schuller et al., 2012).

In retail sale an entire selling job may comprise advising and serving customers as well as taking payment. Taking payment only is the lowest level of division of labour of selling jobs. An entire job in retail sale moreover may combine tasks with different objects of labour, i.e. customers and goods.

Third, data from organisations documenting the assignment of tasks to employees exist already. It is updated 
regularly in most cases in order to enable management decisions. This existing data can be used for an objective and graded operationalization of division of labour by experts with good inter-rater reliability.

Fourth, our more objective operationalization of division of labour based on documentary data corresponds significantly to employee self-reported job requirements, skill utilisation and further learning demands on the job. These mental requirements are higher for higher objective job entirety. Thus, the central decision in job design and redesign concerning the allocation of tasks to individuals, predicts self-reported mental job requirements.

However, the increase of reported mental requirements with additionally assigned tasks is limited. Combining an already entire working process, comprising preparation, implementation and checking of results, with further tasks does not significantly enhance self-reported mental requirements. An explanation of this limitation may offer the limited capacity of deliberate information processing, especially of working memory (Baddeley, 2012).

Further, no clear association was shown for expert-rated division of labour and self-reported mental difficulties. An explanation might be the aforementioned increase of self-reported skill utilisation as well as of the possibilities of learning on the job with increasing job entirety. These characteristics may compensate for difficulties which might arise with increasing complexity of less fragmented jobs.

In contrast to the significant association of objective task entirety and increasing self-reported mental requirements, skill utilisation and learning offers, the literature describes no significant association between selfreported task identity and other relevant self-reported mental requirements. This is summarized in the review of Morgeson and Humphrey (2006) for self-reported work scheduling autonomy, decision-making autonomy, work-methods autonomy, task variety, significance, feedback from job and information processing. The only exception is problem solving.

Obviously, research designed to compare self-reported task identity and more objective measures of division of labour is necessary.

\subsection{Theoretical Implications}

In order to explain theoretically the association between increasing self-reported mental requirements, skill utilisation and learning offers and increasing objective job entirety or decreasing division of labour respectively two approaches should be considered:

The approach of entire or complete activity of ART predicts for jobs comprising phases of preparation, organisation, implementation and checking of results more comprehensive mental requirements, utilisation of skills and knowledge, and possibilities of learning by doing than for fragments of an entire activity (Frese \& Sabini, 1985; Ginsburg et al., 1985; Hacker, 2003; Miller et al., 1960).

Further, self-reported task variety-a component of the Motivation Potential Score (Hackman \& Oldman, 1980)—significantly corresponds with some further self-reported task characteristics such as mental requirements and skill utilisation (Morgeson \& Humphrey, 2006, 2008; Zaniboni et al., 2013). However, there is no reason to suppose that increasing task variety will necessarily result in a complete activity in terms of ART with preparation, organisation, implementation and checking. Accordingly, the review of Morgeson and Humphrey (2006) did not identify a significant intercorrelation of self-reported task variety and self-reported task identity.

Thus, the increase of self-reported mental requirements with decreasing objective division of labour in our study might be due to both more complete jobs in terms of ART, as well as higher task variety-whether resulting in a complete job or not. Our results may not distinguish between these alternatives. Further research regarding this issue is necessary.

\subsection{Practical Implications}

Our results contribute to four practical implications.

First, beyond the often reported relationship between self-reported entire units of work and self-reported mental job requirements, there are associations between the objective assignment of tasks to individuals in job design and employee reported mental requirements. Thus, the assignment of tasks to individuals is a proactive means for determining future job requirements.

Second, already existing documentary data of organisations are suitable to identify levels of division of labour, which determine employee mental requirements.

Third, in job design definitions of intended results are necessary. For this reason self-reported whole units or 
entire pieces of work should be operationalized more precisely in terms of complete activities comprising preparation (goal setting, planning, decision making), organisation of cooperation, implementation, and checking of results-closing, thus, the feedback circle, a prerequisite of learning on the job (cf. the TOTE (test-operate-test-exit)-units; Miller et al., 1960).

Fourth, this way a more direct comparison of existing job design with the requirements of the standards on well-designed jobs (especially EN ISO 6385, 2004) is made possible.

\subsection{Limitations and Further Directions of Research}

Our cross-sectional pilot study has several limitations which point to further directions of research:

Our samples are limited as to the variety of job demands and, thus, need enlargement. The impact of division of labour investigated here is limited to some self-reported mental job requirements. Further job requirements and work outcomes are to be examined in a next step. Further, a possible mediating effect of self-reported task identity on the relationship of objective division of labour to self-reported mental job requirements and work outcomes should be tested. As previously mentioned, the relationship of objective division of labour versus selfreported task identity to self-reported job requirements is to be compared systematically.

Also the impact of different objects of labour (customers, goods) in the division of labour in human services jobs should be considered in further research on assignment of tasks to individuals in job design or redesign.

\subsection{Conclusion}

An objective measure of task assignment to individuals, i.e. division of labour, may avoid common method bias in job design research. Regularly updated data from organisations documenting assignment of tasks already exist. For reasons of job (re-)design the proposed objective scale with well-defined levels of job entireness "whole units of work" may be useful. The more objective operationalization of division of labour based on documentary data corresponds significantly to employees' self-reported job demands, skill utilisation, and further learning demands on the job: The higher the objective task entireness is, the higher the self-reported mental demands are.

Thus, the central decision in job (re-)design, i.e. the assignment of tasks to individuals, predicts essential selfreported mental job requirements. However, adding further tasks to jobs which objectively are already "a whole unit of labour" does not result in a further improvement of self-reported requirements.

\section{Acknowledgements}

We would like to thank all participants in the study.

This research was supported by the Deutsche Forschungsgemeinschaft (DFG grant LO 1173/1-2).

\section{References}

Baddeley, A. (2012). Working Memory: Theories, Modules, and Controversies. Annual Review of Psychology, 63, 1-29. http://dx.doi.org/10.1146/annurev-psych-120710-100422

Bakker, A. B., \& Demerouti, E. (2007). The Job Demands-Resources Model: State of the Art. Journal of Managerial Psychology, 22, 309-328. http://dx.doi.org/10.1108/02683940710733115

Bakker, A. B., van Veldhoven, M., \& Xanthopoulou, D. (2010). Beyond the Demand-Control Model: Thriving on High Job Demands and Resources. Journal of Personnel Psychology, 9, 3-16. http://dx.doi.org/10.1027/1866-5888/a000006

Berkhout, A. B., Boumans, N. G., Frans, J. N., N., Van Breukelen, G. J., \& Abu-Saad, H. (2003). Effects of ResidentOriented Care on Job Characteristics of Nursing Caregivers. Work \& Stress, 17, 337-353. http://dx.doi.org/10.1080/02678370310001647645

Bolton, S. C. (2004). A Simple Matter of Control? NHS Hospital Nurses and New Management. Journal of Management Studies, 41, 317-333. http://dx.doi.org/10.1111/j.1467-6486.2004.00434.x

Brusoni, S. (2005). The Limits to Specialization: Problem Solving and Coordination in "Modular Networks”. Organization Studies, 26, 1885-1907. http://dx.doi.org/10.1177/0170840605059161

Cacciatori, E., Tamoschus, D., \& Grabher, G. (2012). Knowledge Transfer across Projects: Codification in Creative, HighTech and Engineering Industries. Management Learning, 43, 309-331. http://dx.doi.org/10.1177/1350507611426240

Carter, B., \& Stevenson, H. (2012). Teachers, Workforce Remodelling and the Challenge to Labour Process Analysis. Work, Employment \& Society, 26, 481-496. http://dx.doi.org/10.1177/0950017012438579 
Cordery, J. L., \& Parker, S. K. (2012). Job and Role Design. In S. Kozlowski (Ed.), The Oxford Handbook of Industrial and Organizational Psychology (Chapter 9). Oxford: Oxford University Press.

Demerouti, E., Bakker, A. B., Nachreiner, F., \& Schaufeli, W. B. (2001). The Job Demands—Resources Model of Burnout. Journal of Applied Psychology, 86, 499-512. http://dx.doi.org/10.1037/0021-9010.86.3.499

Debitz, U., Gruber, H., \& Richter, G. (2001). Psychische Gesundheit am Arbeitsplatz Teil 2: Erkennen, Beurteilen und Verhüten von Fehlbeanspruchungen. Bochum: Verlag Technik \& Information.

Diehl, J. M., \& Arbinger, R. (2001). Einführung in die Inferenzstatistik [Introduction to Inferential Statistics] (3rd ed.). Eschborn: Verlag Dietmar Klotz.

DIN EN 614-2 (2002). Safety of Machinery_Ergonomic Design Principles_Part 2: Interactions between the Design of Machinery and Work Tasks. German Version EN 614-2:2000 +A1: 2008.

EN ISO 6385 (2004). Ergonomic Principles in the Design of Work Systems.

Frese, M., \& Sabini, J. (1985). Goal-Directed Behavior: The Concept of Action in Psychology. Hillsdale, NJ: Erlbaum.

Ginsburg, G. P., Brenner, M., \& von Cranach, M. (1985). Discovery Strategies in the Psychology of Action. London/New York: Academic Press.

Goodale, M. A., \& Westwood, D. A. (2004). An Evolving View of Duplex Vision: Separate but Interacting Cortical Pathways for Perception and Action. Current Opinion in Neurobiology, 14, 203-211. http://dx.doi.org/10.1016/j.conb.2004.03.002

Grimaldi, R., \& Torrisi, S. (2001). Codified-Tacit and General-Specific Knowledge in the Division of Labour among Firms: A Study of the Software Industry. Research Policy, 30, 1425-1442. http://dx.doi.org/10.1016/S0048-7333(01)00160-3

Gross, J. J. (1998a). Antecendent- and Response-Focussed Emotion Regulation: Divergent Consequences for Experience, Expression, and Physiology. Journal of Personality and Social Psychology, 74, 224-237.

http://dx.doi.org/10.1037/0022-3514.74.1.224

Gross, J. J. (1998b). The Emerging Field of Emotion Regulation: An Integrative Review. Review of General Psychology, 2, 271-299. http://dx.doi.org/10.1037/1089-2680.2.3.271

Grönlund, A. (2012). On-the-Job Training-A Mechanism for Segregation? Examining the Relationship between Gender, Occupation, and On-the-Job Training Investments. European Sociological Review, 28, 408-420. http://dx.doi.org/10.1093/esr/jcr007

Hacker, W. (2003). Action Regulation Theory: A Practical Tool for the Design of Modern Work Processes? European Journal of Work and Organizational Psychology, 12, 105-130. http://dx.doi.org/10.1080/13594320344000075

Hacker, W., Fritsche, B., Richter, P., \& Iwanowa, A. (1995). Tätigkeitsbewertungssystem. In E. Ulich (Ed.), Reihe Mensch; Technik und Organisation (Band 7). Zürich: vdf.

Hackman, J. R., \& Oldham, G. R. (1980). Work Redesign. Reading, MA: Addison-Wesley.

Humphrey, S. E., Nahrgang, J. D., \& Morgeson, F. P. (2007). Integrating Motivational, Social, and Contextual Work Design Features: A Meta-Analytic Summary and Theoretical Extension of the Work Design Literature. Journal of Applied Psychology, 92, 1332-1356. http://dx.doi.org/10.1037/0021-9010.92.5.1332

IHK Chemnitz (2014). Situation des Einzelhandels 2014 [Situation of the Retail Trade 2014]. http://www.chemnitz.ihk24.de/linkableblob/cihk24/servicemarken/branchen/Handel/Publikationen/1592086/.16./data/Stud ie_zur_Situation_des_Einzelhandels_2011-data.pdf

Karasek, R., \& Theorell, T. (1990). Healthy Work: Stress, Productivity, and the Reconstruction of Working Life. New York: Basic Books.

Lewin, K. (1926). Untersuchungen zur Handlungs- und Affektpsychologie II: Vorsatz, Wille und Bedürfnis [Analyses of Psychology of Action and Affect: Intention, Will, and Need]. Psychologische Forschung, 7, 330-385. http://dx.doi.org/10.1007/BF02424365

Lewin, K., \& Rupp, H. (1928). Untersuchungen in der Textilindustrie [Analyses in Textile Industry]. Psychotechnische Zeitschrift, 3, 3-18.

Luria, A. R. (1973). The Working Brain: An Introduction to Neuropsychology. Harmondsworth: Penguin Books.

Martin, G. P., Currie, G., \& Finn, R. (2009). Reconfiguring or Reproducing Intra-Professional Boundaries? Specialist Expertise, Generalist Knowledge and the Modernization of the Medical Workforce. Social Science \& Medicine, 68, 1191-1198. http://dx.doi.org/10.1016/j.socscimed.2009.01.006

Miller, G. A., Galanter, E., \& Pribram, K. H. (1960). Plans and the Structure of Behavior. New York: Holt.

Morgeson, F. P., \& Humphrey, S. E. (2006). The Work Design Questionnaire (WDQ): Development and Validating a Comprehensive Measure for Assessing Job Design and the Nature of Work. Journal of Applied Psychology, 91, 1321-1339. http://dx.doi.org/10.1037/0021-9010.91.6.1321 
Morgeson, F. P., \& Humphrey, S. E. (2008). Job and Team Design: Toward a More Integrative Conceptualization of Work Design. In J. Martoccio (Ed.), Research in Personnel and Human Resource Management (pp. 39-91). Bingley: Emerald Group Publishing Limited. http://dx.doi.org/10.1016/S0742-7301(08)27002-7

Pietrzyk, U., Rodehacke, S., \& Hacker, W. (2012). FEMIA-Fragebogen zur Ermittlung wahrgenommener Merkmale interaktiver Arbeitstätigkeiten [Retail Sales Task Questionnaire]. Zeitschrift für Arbeits- und Organisationspsychologie, 56, 186-201. http://dx.doi.org/10.1026/0932-4089/a000087

Podsakoff, P. M., MacKenzie, S. M., Lee, J., \& Podsakoff, N. P. (2003). Common Method Variance in Behavioral Research: A Critical Review of the Literature and Recommended Remedies. Journal of Applied Psychology, 88, 879-903. http://dx.doi.org/10.1037/0021-9010.88.5.879

Richter, G., \& Hacker, W. (2003). Tätigkeitsbewertungssystem—Geistige Arbeit für Arbeitsplatzinhaber. In E. Ulich (Ed.), Reihe Mensch, Technik und Organisation (Band 35). Zürich: vdf.

Salhani, D., \& Coulter, I. (2009). The Politics of Interprofessional Working and the Struggle for Professional Autonomy in Nursing. Social Science \& Medicine, 68, 1221-1228. http://dx.doi.org/10.1016/j.socscimed.2009.01.041

Schuller, K., Roesler, U., \& Rau, R. (2012). Self-Reported Job Characteristics and Negative Spillover from Work to Private Life as Mediators between Expert-Rated Job Characteristics and Vital Exhaustion. European Journal of Work and Organizational Psychology, 23, 177-189. http://dx.doi.org/10.1080/1359432X.2012.727555

Sims, H. P., Szilagyi, A. D., \& Keller, R. T. (1976). The Measurement of Job Characteristics. Academy of Management Journal, 19, 195-212. http://dx.doi.org/10.2307/255772

Stegmann, S., van Dick, R., Ullrich, J., Charalambous, J., Menzel, B., Egold, N., \& Tai-Chi Wu, T. (2010). Der Work Design Questionnaire: Vorstellung und Validierung einer deutschen Version [Work Design Questionnaire-German Version]. Zeitschrift für Arbeits- und Organisationspsychologie, 54, 1-28. http://dx.doi.org/10.1026/0932-4089/a000002

Zaniboni, S., Truxillo, D. M., \& Fraccaroli, F. (2013). Differential Effects of Task Variety and Skill Variety on Burnout and Turnover Intentions for Older and Younger Workers. European Journal of Work and Organizational Psychology, 22, 306-317. http://dx.doi.org/10.1080/1359432X.2013.782288

Zapf, D., Mertini, H., Seifert, C., Vogt, C., Isic, A., \& Fischbach, A. (2000). FEWS (Frankfurt Emotion Work Scales, Frankfurter Skalen zur Emotionsarbeit). Version 4.0. Frankfurt am Main: Johann Wolfgang Goethe-Universität, Institut für Psychologie. 
Scientific Research Publishing (SCIRP) is one of the largest Open Access journal publishers. It is currently publishing more than 200 open access, online, peer-reviewed journals covering a wide range of academic disciplines. SCIRP serves the worldwide academic communities and contributes to the progress and application of science with its publication.

Other selected journals from SCIRP are listed as below. Submit your manuscript to us via either submit@scirp.org or Online Submission Portal.
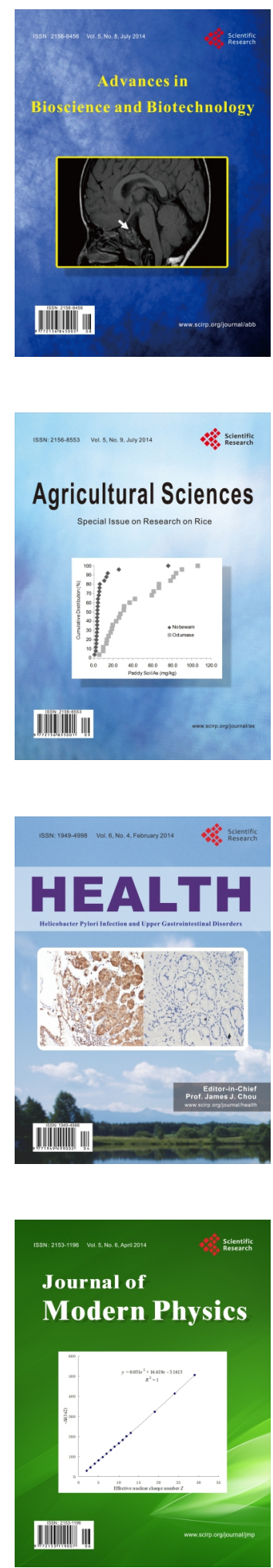
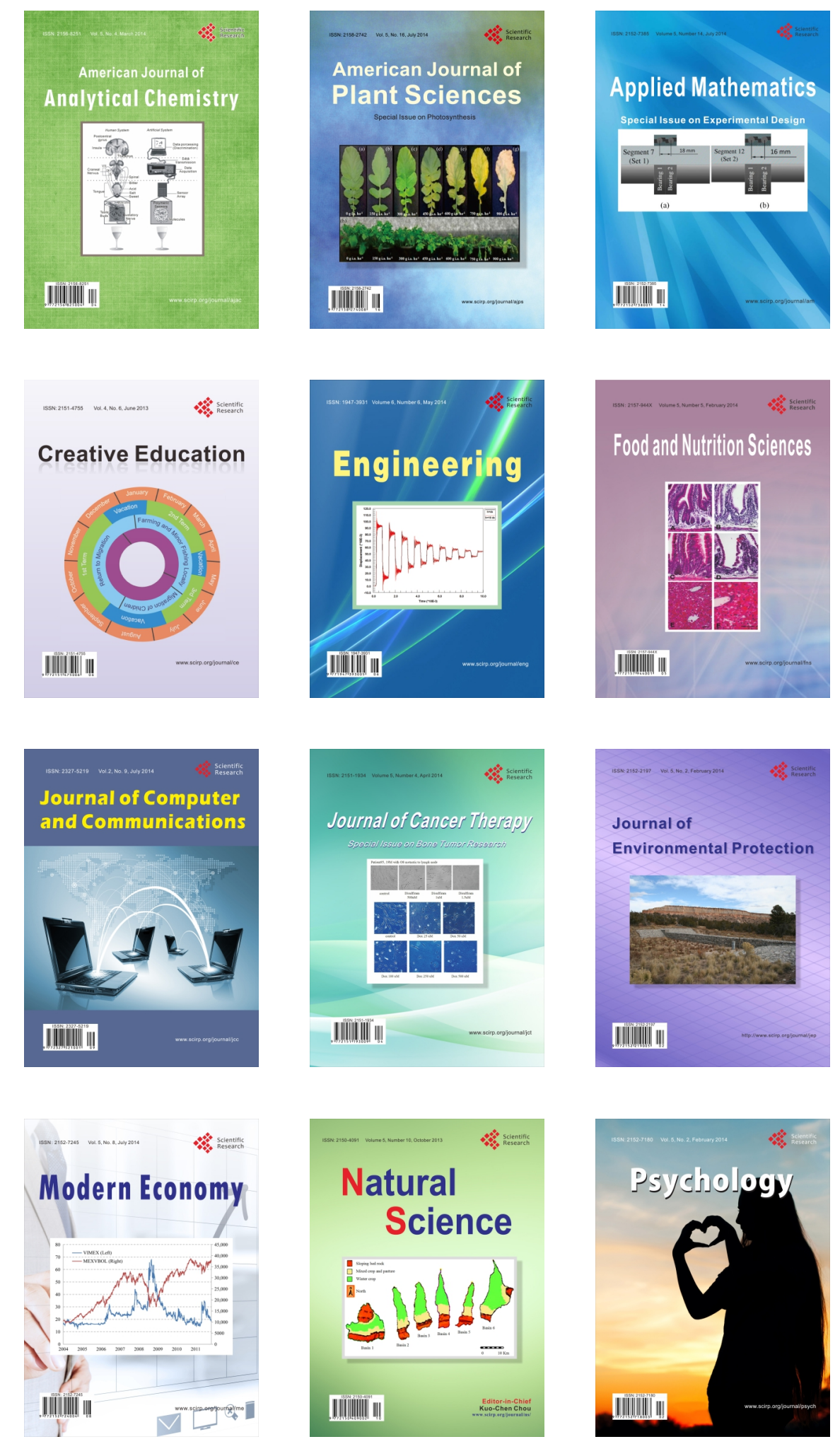